\title{
Big Data \& Analytics as a sustainable Customer Loyalty Instrument in Banking and Finance
}

Carsten Giebe, ORCID: https://orcid.org/0000-0003-2335-4808

PhD Candidate, University Kaposvár, Hungary; Senior Referent Data Analytics, S Rating und Risikosysteme GmbH, Berlin, Germany

Lennart Hammerström, ORCID: https://orcid.org/0000-0003-1382-3092

$\mathrm{PhD}$ Candidate, University Kaposvár, Hungary; Director Operations Engineering Electronics \& Head of Corporate Competence Center Industry 4.0, HELLA GmbH \& Co. KGaA, Lippstadt, Germany

Dirk Zwerenz, ORCID: https://orcid.org/0000-0001-8677-6050

$\mathrm{PhD}$ Candidate, University Kaposvár, Hungary; Head of Major Project Service, German Doka formwork technology GmbH, Maisach, Germany

\begin{abstract}
A strong technological change and changed customer expectations influence the banking sector in Germany. Banks have more data about their customers than other industries. Innovative methods and solutions have been developed on the basis of mathematical-statistical models. This knowledge is used to focus on the customer and is termed as "Big Data \& Analytics" and to be able to offer products that fit exactly from the information gained. The main purpose of this research is to investigate to what extent "Big Data \& Analytics" can be described and used as a sustainable customer loyalty instrument. The examination of the topic is carried out in the following logical order: Introduction, research question and background, methods and hypotheses, disussion and conclusion, limitations and directions for further research. When using Big Data \& Analytics, there are different perspectives, e.g. from the bank's point of view and from the bank client's point of view. In order to answer the question of sustainable customer loyalty from the customer perspective, the relationship between "Big Data \& Analytics" and the principles of customer advisory [a. The customer must be advised objectively. b. The customer must be advised comprehensively. c. The customer must be advised individually and $\mathrm{d}$. The customer must be actively advised] will be investigated. This paper presents the results of an empirical analysis based on a survey from September 2019 in Germany.
\end{abstract}

Keywords: Big Data \& Analytics, Corporate Social Responsibility, Customer Loyalty Instrument, Business Ethics.

JEL Classification: G21, Q56.

Cite as: Giebe, C., Hammerström, L., Zwerenz, D. (2019). Big Data \& Analytics as a sustainable Customer Loyalty Instrument in Banking and Finance. Financial Markets, Institutions and Risks, 3(4), 74-88. http://doi.org/ 10.21272/fmir.3(4). 74-88.2019

(C) The Authors, 2019. This article is published with open access at Sumy State University.

\section{Introduction}

Sustainability should take place in all aspects of the company. For example, in all supply chains or in fundamental management decision-making processes. If this is ensured, resources can be preserved for future generations (Jeble et al., 2018). The process that made sustainable development an important issue on the world stage began in 1987 with the report of the Brundtland Commission of the United Nations. The Commission has identified a number of challenges for mankind. Those include population and human capital, industrial development and urbanisation, food security, energy and species and ecosystems. Increasing worldwide competition is causing companies to compete more fierce. The global increase in social and environmental concerns has forced companies to pay more attention to society and the environment. Companies that acted more intelligent than others used this concept to increase their competitiveness (Rudawska and Renko, 2012). Few seem to deny the importance of Corporate Social Responsibility (CSR). A multiplication of the number of CSR standards and tools can be observed. All decent companies deal with CSR in varying degrees of depth. Things seem to be on course (Tóth, 2007). 
Financial Markets, Institutions and Risks, Volume 3, Issue 4, 2019 ISSN (online) - 2521-1242 ISSN (print) - 2521-1250

A research query sustainability in the banking sector leads to the so-called "green banking". In the past, banks have only been called financial institutions to deal with all financial issues. Moral aspects were not considered for a long time. This public opinion has given banks enormous leeway in complying with ethical standards. For banking experts, Green Banking today includes principles of sustainability, ethical lending, conservation and energy efficiency (Singh and Singh, 2012). Various fields of action and concrete steps are discussed in the literature. These include, for example, the use of online banking as a way of saving paper in the digitalization of business processes. Green banking has the potential to improve bank performance and customer satisfaction (Gupta, 2015). Customer satisfaction automatically leads to customer loyalty (Wilson et al., 2008). In order to be able to answer the question of sustainable customer loyalty, it is necessary to concentrate on customer satisfaction.

The banking sector in Germany is defined by a three-pillar structure. This strict separation takes place in the three pillars of cooperative banks (e.g. DZ-Bank), private commercial banks (e.g. Deutsche Bank, Commerzbank) and public institutions (e.g. savings banks). Over the last decade, the impact of digital technologies has had a huge impact on the daily lives of banks and their customers. Many banks in Germany could lose touch with the age of digital transformation. Banks in Germany are therefore well advised to offer innovative banking services and to define new processes. There are various activities in the German banking landscape that deal with digital innovations, such as chatbots or the use of Big Data \& Analytics (BD\&A) (Giebe, 2019). Today, Big Data \& Analytics solutions can be found in almost every industry segment. Whether in the healthcare industry or e-commerce, the benefits of analysis are proven. However, large amounts of data themselves do not generate added value. But the combination of expert knowledge and the application of analytical methods can provide valuable impulses. Big Data \& Analytics can help draw the right conclusions and provide valuable insights into non-obvious patterns and relationships. The analysis is often characterised by a combination of different methods and can provide assistance for decisions (Hammerström, 2018). The development of specific competencies to ensure the digital transformation of the financial sector is currently one of the greatest challenges. The aim is to secure competitiveness and sustainable business. Changes in the demand for new solutions and technological competencies of the company are currently being observed. This includes, for example, the improvement of existing products or product positioning (Mavlutova and Volkova, 2019). For banks in Germany, Big Data \& Analytics can be used to better position products.

But how do Big Data \& Analytics and CSR fit together? According to Hammerström et. al, investment decisions in Big Data \& Analytics are often influenced by the desire to optimize the existing business. Big Data \& Analytics is used to improve the competitive position. From the authors' point of view, CSR is unfortunately in most cases not a primary reason for using Big Data \& Analytics. However, the results achieved by Big Data \& Analytics are most frequently published in corporate sustainability reports (Hammerström et al., 2019). Companies that invest in the right talent and foster a culture of knowledge sharing are also more successful at building Big Data \& Analytics capabilities. Big Data \& Analytics has a major impact on social and environmental performance. Empirical results show that Big Data \& Analytics offers significant benefits for environmental and social activities (Dubey et al., 2017).

Customer satisfaction is in the great interest of scientists and companies. Maximizing profits and reducing costs are the main goals of companies. One of the factors that can have a positive effect on sales growth is customer satisfaction. This is the result of repeat purchases and recommendations from customers (Wilson et al., 2008). Various definitions of customer satisfaction can be found in the scientific literature. They vary according to the degree of specificity and can be distinguished as follows (Zeithaml et al, 1993).

Table 1. Types of customer satisfaction

\begin{tabular}{|l|c|}
\multicolumn{1}{|c|}{$\begin{array}{c}\text { Definition } \\
\text { Customer Satisfaction }\end{array}$} & Influence on the Research work of this article \\
\hline Satisfaction with the product & YES \\
\hline Satisfaction with the decision to gain experience & NO \\
\hline Satisfaction with performance features & YES \\
\hline Satisfaction with the experience of consumption & YES \\
\hline Satisfaction with institutions and companies & YES \\
\hline Satisfaction in connection with the experience before the purchase & NO \\
\hline
\end{tabular}

Source: compiled by the authors.

In the definitions of satisfaction, we find that there seems to be a difference between satisfaction with manufacturing and satisfaction with service providers. Our research aims at satisfaction with the banking product, satisfaction with the performance characteristics of the banking product, satisfaction with the experience of consumption (with advice) and, in a broader sense, satisfaction with the institutions, i.e. the 
ISSN (online) - 2521-1242 ISSN (print) - 2521-1250

banking sector in Germany. Within the scope of the study, however, we did not allocate the question of satisfaction to it, but looked at it in general terms.

\section{Literature Review}

The challenge was to bundle the topics Banking and Finance, Big Data \& Analytics as well as Corporate Social Responsbility. Furthermore, it was our aim to effectively supplement the practical component through the "principles of customer advisory services" with scientific articles. That's the reason why there are three main categories of literature that we have used to work on this article. The first category is literature on the banking sector and digital transformation (Corneliu 2013, David et al. 2016 and Giebe 2019). The second category of literature is research specifically on Big Data \& Analytics. Here the works of Dubey et al. 2017, Hammerström 2018 and Fuschi \& Tvaronavičiene can be named as examples. The third category is the literature that has enabled us to identify backgrounds on Customer Social Responsibility. These include Gupta 2015, Hammerström et. al 2019 and Kerekes \& Wetzker 2013. From each category we have researched valuable content and enriched it with our own impulses.

\section{Research question and background:}

Within the framework of the three-year vocational training as a banker, the following so called principles of customer advisory services ${ }^{3}$ apply in Germany (see Table 2). In accordance with these principles, client advisors are required to advise their clients to the best of their knowledge and belief. As a rule, the human factor is manifold involved, on the customer side and on the bank advisors side. There is a widespread phenomenon in banking practice. There is a tension between the pursuit of profit through commissions and the principles of customer advice. Often the bank advisors do not necessarily sell the products that bring the most commission or that the advisors have on their target card, what is best for the customers. This is very questionable from an ethical point of view. Big Data \& Analytics is intended to remedy this situation. This is understood to mean the scientific procedure of obtaining large amounts of data from different data sources in order to apply algorithms to them. These algorithms learn data correlations and thereby enable forecasts to support business decisions. As already mentioned, algorithms can recognize which customers are affine for certain products. The assumption is that if customers are only offered the banking products for which they actually have an affinity, there is social sustainability. The objective should be that no customer should be subordinated exclusively to the economic interests of a bank.

Table 2. Principles of client advisory services

\begin{tabular}{|l|l|}
\hline \multicolumn{1}{|c|}{ Principles of customer advisory services } & \multicolumn{1}{c|}{ Example for explanation } \\
\hline The customer must be advised objectively & $\begin{array}{l}\text { The consultation must be open about the benefits and the risks of the chosen } \\
\text { form of investment are taken into account. }\end{array}$ \\
\hline The customer must be advised comprehensively & $\begin{array}{l}\text { The client must be aware of the risks of the investment, Security, availability } \\
\text { and profitability } \\
\text { be comprehensively informed. }\end{array}$ \\
\hline The customer must be advised individually & $\begin{array}{l}\text { The advisor must be able to identify the personal and financial the customer's } \\
\text { circumstances and to provide the customer with a in accordance with his } \\
\text { wishes, investment objectives and advise on possibilities. }\end{array}$ \\
\hline
\end{tabular}

Source: compiled by the authors.

There are different perspectives in customer advisory services, those of the bank customer (01), those of the bank advisor (02) and those of the bank (03). The bank is interested in a lifelong relationship with its customers. The bank advisor is employed by the bank and sells its products to bank customers. The bank client is a customer of the bank and has usually consciously opted for this partnership. As part of this research, we focus on the perspective of the bank client. Because only bank customers themselves can directly assess their views on various aspects best.

\footnotetext{
${ }^{3}$ http://www.bankazubi.de/wissenspool/artikel.php?opid=1 achgebietid=1 atid=9rtikelid=17
} 


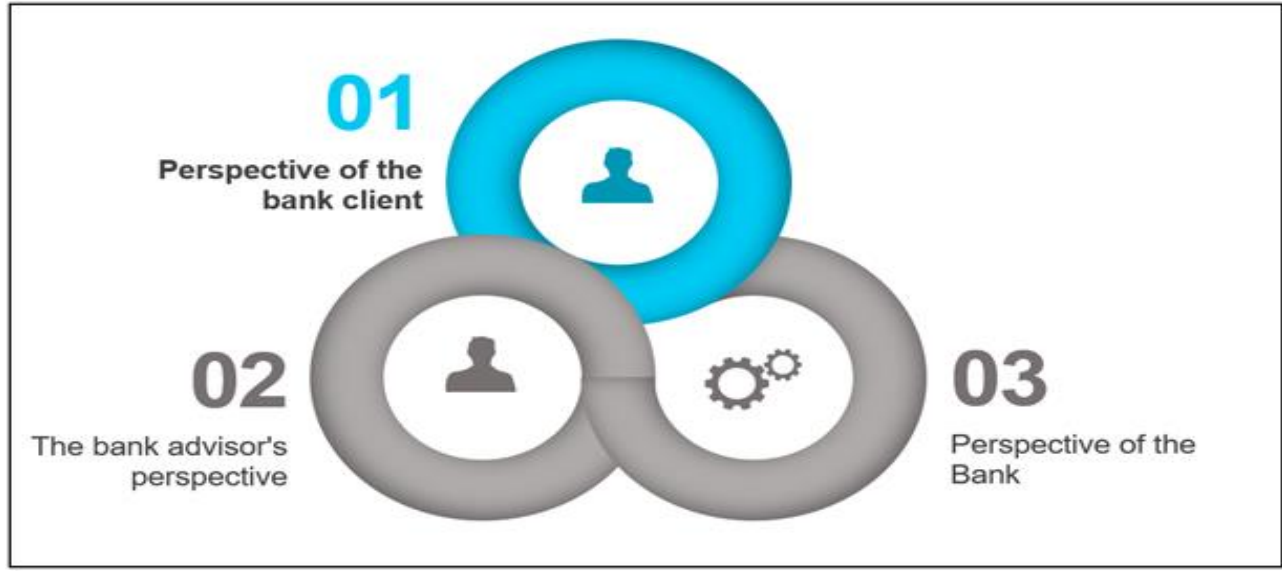

Figure 1. Various perspectives in customer advisory services

Source: compiled by the authors.

\section{Research question:}

Does Big Data \& Analytics improve the quality of consulting from the customer's perspective (measured against the principles of client advisory services) and has a lasting influence on customer loyalty?

We analyze the following statements:

1. Big Data \& Analytics ensures greater customer loyalty from the point of view of bank customers.

2. Big Data \& Analytics ensures more objective advice for bank customers.

3. Big Data \& Analytics ensures more comprehensive advice for bank customers.

4. Big Data \& Analytics ensures more individual advice for bank customers.

5. Big Data \& Analytics ensures more proactive advice for bank customers.

6. The age plays no significant role in answering the research question.

\section{Methods and hypotheses}

In order to answer the research question, a survey was initiated. This survey was carried out online at www.surveymonkey.de. The premise was a simple and quick answer. The survey period was from 01.09.2019 to 30.09.2019. The assumption is that each participant is of age and a bank customer in in Germany. A total of 122 bank customers took part in the survey. We opted for a four-stage Likert scale because, for example, we did not want to allow "abstentions" or a "tendency towards the middle". Statistical hypotheses, the significance of which has been tested, are used to examine the above six statements.

\section{The original text of the survey was:}

"Big Data \& Analytics" (the analysis of large amounts of data) is a collective term for statistical-mathematical methods that enable the bank advisors, for example, to forecast which customers have an affinity for a banking product.

If you yourself are a customer of a bank in Germany, we would be pleased to receive your participation in the survey, which consists of six questions. Only one answer is possible for each question. With the help of this survey, the influence of Big Data \& Analytics (in contrast to the approach without the use of Big Data \& Analytics) on customer loyalty is to be investigated.

Statement 1: Age - How old are you?

Indication of the respective age

Statement 2: Big Data \& Analytics ensures more objective consulting.

$>$ True

$>$ More true

$>$ More not true

$>$ Not true 
Financial Markets, Institutions and Risks, Volume 3, Issue 4, 2019

ISSN (online) - 2521-1242 ISSN (print) - 2521-1250

Statement 3: Big Data \& Analytics provides more comprehensive advice.

$>$ True

$>$ More true

$>$ More not true

$>$ Not true

Statement 4: Big Data \& Analytics provides more individual advice.

$>$ True

$>$ More true

$>$ More not true

$>$ Not true

Statement 5: Big Data \& Analytics ensures more active consulting.

$>$ True

$>$ More true

$>$ More not true

$>$ Not true

Statement 6: Do you agree with the statement that Big Data \& Analytics ensures higher customer loyalty?

$>$ Yes

$>$ No

Results of the survey:

Information on the age structure of participants in the Big Data \& Analytics survey

When asked "How old are you?", respondents were asked to indicate their age. Among the 122 participants, the top three were the following age groups: [1] With 9 participations the age "33", [2] with 8 participations the age " 39 and [3] with 7 participations the age " 40 ". The age groups with only one voice at a time were the taillights: $26,38,44,48,50,54$ and 60 .

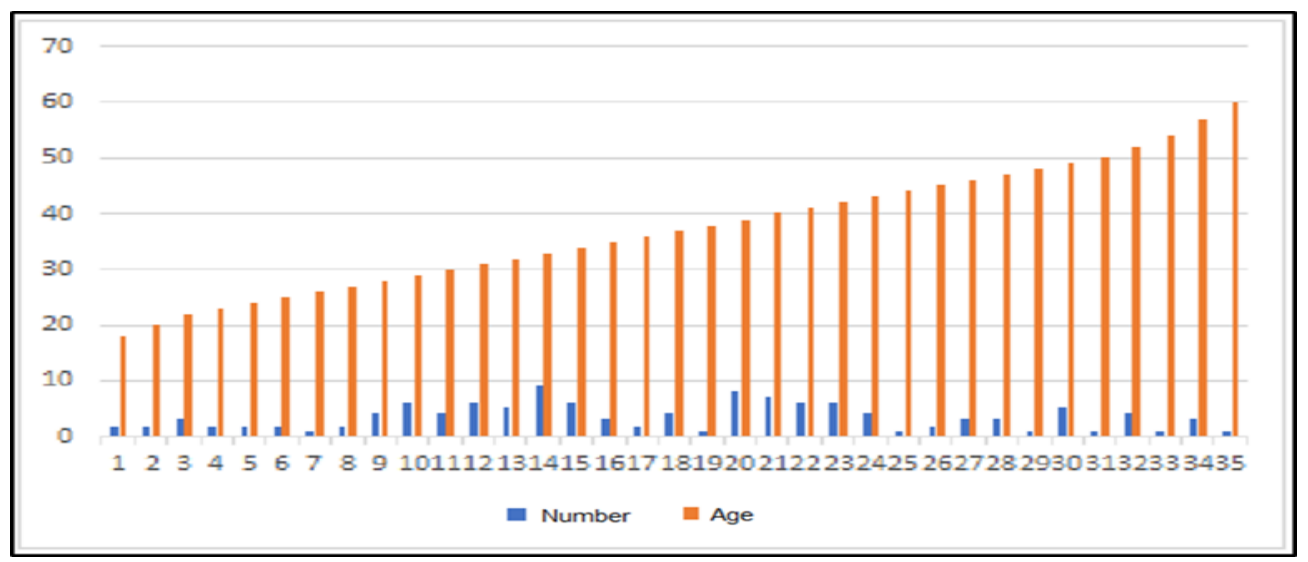

Graph 1. Distribution of the age of the survey participants

Source: compiled by the authors.

Big Data \& Analytics ensures more objective consulting

There were four possible answers to the question "Big Data \& Analytics ensures more objective advice": [1] True, [2] More true, [3] More not true and [4.] Not true. As the graph on the left shows, $27.05 \%$ of respondents chose the answer "True", $54.10 \%$ chose the answer "True", $14.75 \%$ chose the answer "True", and $4.10 \%$ chose the answer "True". 


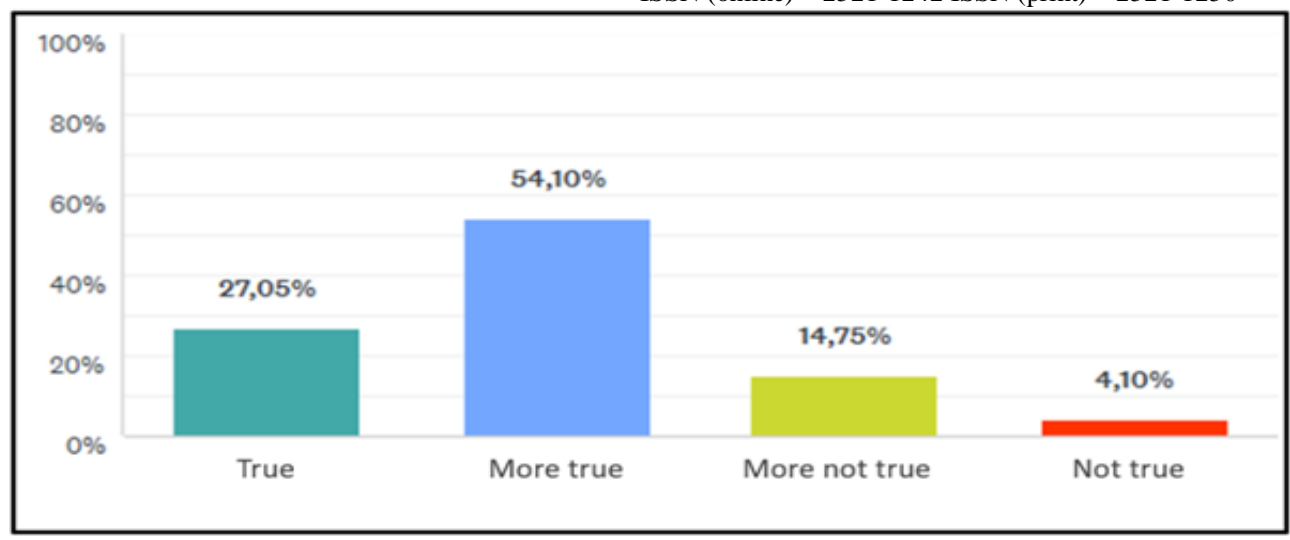

Graph 2. BD\&A provides more objective advice

Source: compiled by the authors.

\section{Big Data \&Analytics provides more comprehensive advice}

There were four possible answers to the question "Big Data \& Analytics provides more comprehensive advice": [1] True, [2] More true, [3] More not true and [4.] Not true. As the graph on the left shows, 18.03\% of respondents chose the answer "Applies", 50.82\% chose the answer "Applies", 24.59\% chose the answer "Applies", and 6.56\% chose the answer "Applies".

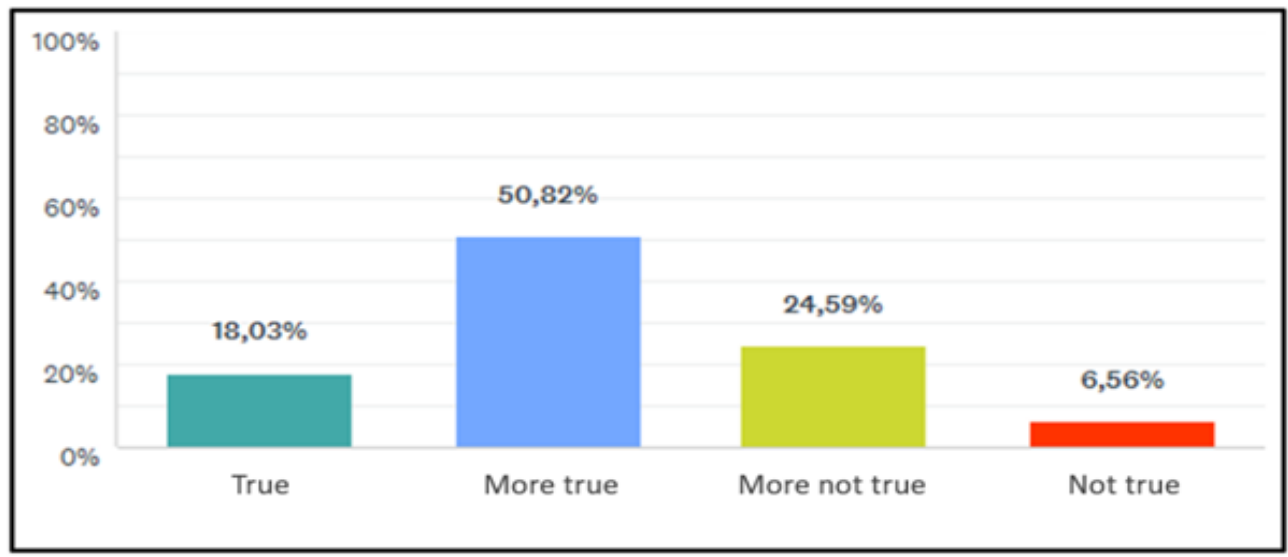

Graph 3. BD\&A provides more comprehensive advice

\section{Big Data \& Analytics ensures more individual advice}

There were four possible answers to the question "Big Data \& Analytics ensures more individual advice": [1] True, [2] More true, [3] More not true and [4.] Not true. As the graph on the left shows, 27.87\% of respondents chose the answer "Applies", 41.80\% chose the answer "Applies", 22.13\% chose the answer "Applies", and $8.20 \%$ chose the answer "Applies".

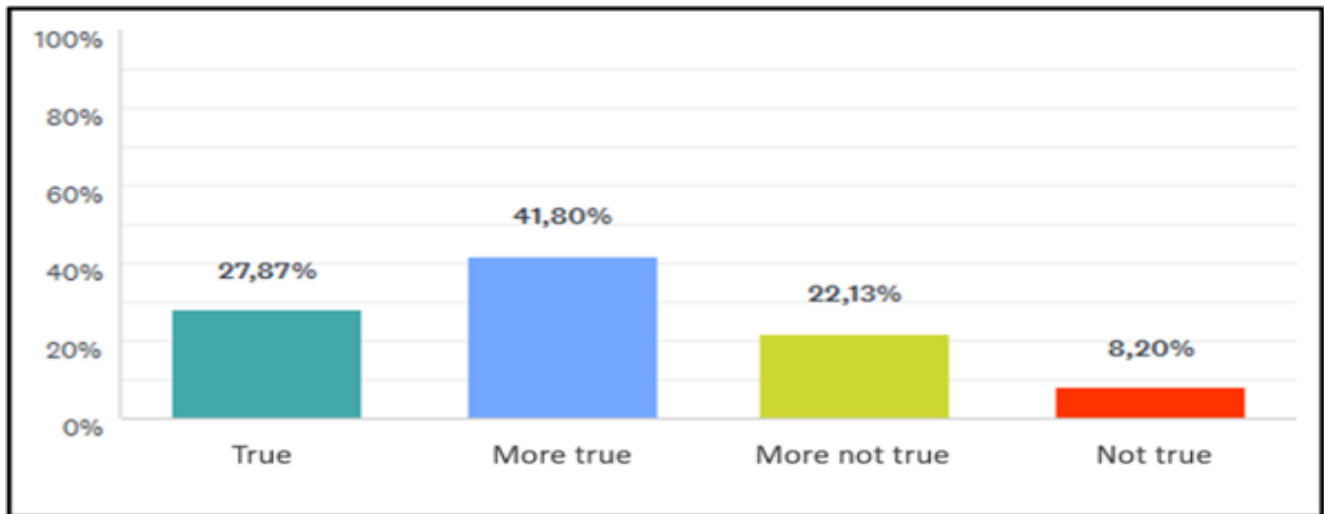

Graph 4. BD\&A provides for a more individual advice

Source: compiled by the authors.

Big Data \& Analytics provides more active advice 
There were four possible answers to the question "Big Data \& Analytics ensures more active advice": [1] True, [2] More true, [3] More not true and [4.] Not true. As the graph on the left shows, $27.05 \%$ of respondents chose the answer "True", $45.90 \%$ chose the answer "True", $18.85 \%$ chose the answer "True", and $8.20 \%$ chose the answer "True".

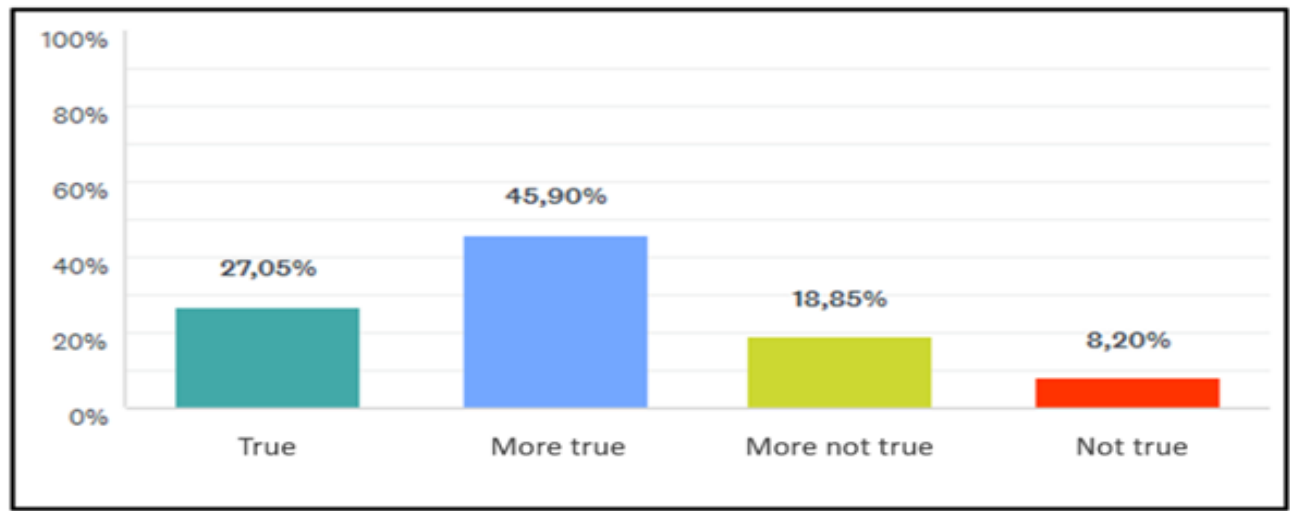

Graph 5. BD\&A ensures more active advice

Source: compiled by the authors.

Do you agree with the statement that Big Data \& Analytics ensures higher customer loyalty?

When asked, "Do you agree with the statement that Big Data \& Analytics helps increase customer loyalty? " there were two possible answers: [1] Yes and [2] No. As the graph on the left shows, 66.39\% of respondents chose "Yes" and $33.61 \%$ chose "No".

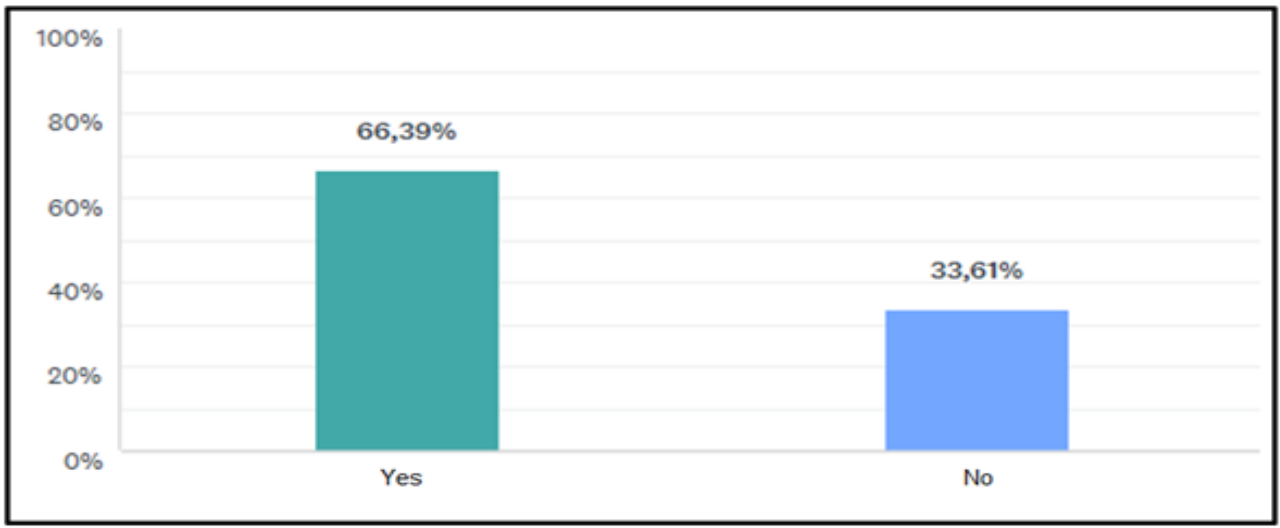

Graph 6. BD\&A ensures higher customer loyalty

Source: compiled by the authors.

\section{Results and discussion}

Within the framework of inductive statistics, the statistical software " $\mathrm{R}$ " was used to refute or prove hypotheses with statistical tests. These statistical tests were carried out with a significance level of $\alpha=0.05$. For the data preparation we downloaded the data from www.surveymonkey.de and coded the values of the Likert scale numerically (e.g. "applies" value 1 and "does not apply" value 4). The characteristics of the questions with possible answers "yes" and "no" were binary coded. In our research, various statistical tests were used and selected according to the respective scale level.

\section{Statement 1:}

Big Data \& Analytics ensures greater customer loyalty from the point of view of bank customers.

The test persons answered the questions independently of each other. Therefore, the answers to the questions can be modelled as "Bernoulli"-distributed random variables. The probability that a bank customer will respond positively to this question is referred to as p_pos.

Hypothesis: $H_{0}: p \_p o s \leq 0.5$ 
Financial Markets, Institutions and Risks, Volume 3, Issue 4, 2019

ISSN (online) - 2521-1242 ISSN (print) - 2521-1250

The probability that a randomly selected respondent responds positively to the question about customer loyalty is $\leq 0.5$ (less than $50 \%$ of participants).

Alternative hypothesis: $H_{1}:$ p_pos $>0.5$

The probability that a randomly selected respondent will respond positively to the question about customer loyalty is $>0.5$ (more than $50 \%$ of participants).

To answer the hypothesis, an (exact) binomial test was performed. The test variable is the number of positive responses and binomially distributed under the hypothesis (with $\mathrm{p}=\mathrm{p} \_$pos and $\mathrm{n}=122$ ).

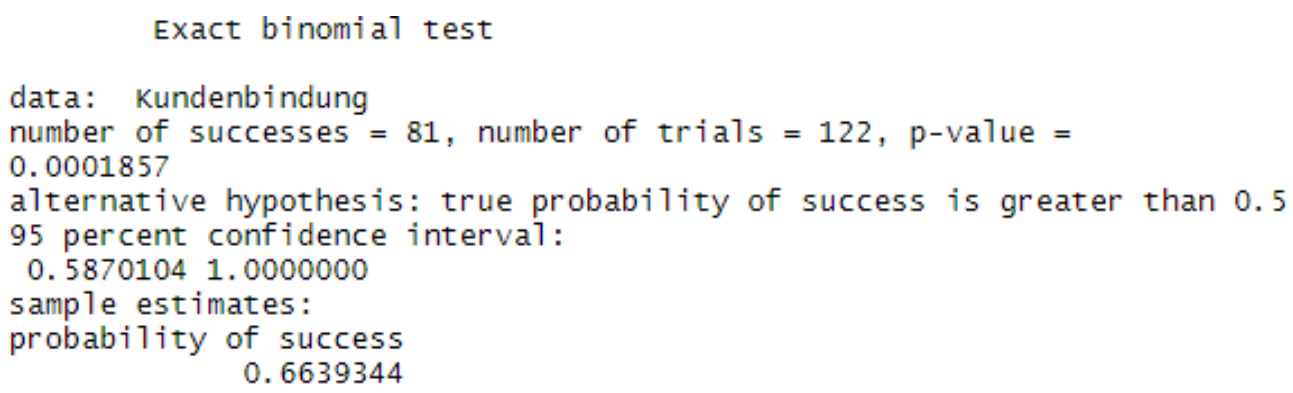

Result: The hypothesis was statistically refuted, since the $\mathrm{p}$-value $=0.0001857<0.05$.

Big Data \& Analytics ensures greater customer loyalty from the point of view of bank customers.

\section{Statement 2:}

Big Data \& Analytics ensures more objective advice for bank customers.

What we want to investigate is: "How big is the influence of more objective consulting on the question of higher customer loyalty?

Procedure: For each of the 122 bank clients we received a statement regarding the more objective advice. We know which of the bank customers have concluded that DA ensures higher customer loyalty, and which do not. According to this assessment, we can "dichotomize" bank customers.

Now we test whether there is a significant difference in answering the question (for a more objective consultation).

Background: 122 bank customers answered "yes" or "no" to the question of whether BD\&A ensures greater customer loyalty. So, we have two groups, the "Yes" and the "No" answering machine. We can now compare whether both groups would have answered the question of more objective advice in roughly the same way. We would like to see that the "yes-men" also plead for more objective advice.

What we have now tested is the question of a difference between the two groups.

Since the Wilcoxon rank sum test is a non-parametric test, no formulas can be used as hypotheses. The test checks whether the two same groups originate from the population.

Hypothesis: Both groups are from the same basic population. This means that, on average, the two groups formed would answer the question similarly.

Alternative hypothesis: Both groups do not originate from the same basic population.

In order to answer the hypothesis, a Wilcoxon rank-sum test was chosen because there is an ordinal scale level (Likert scale) with ranking.

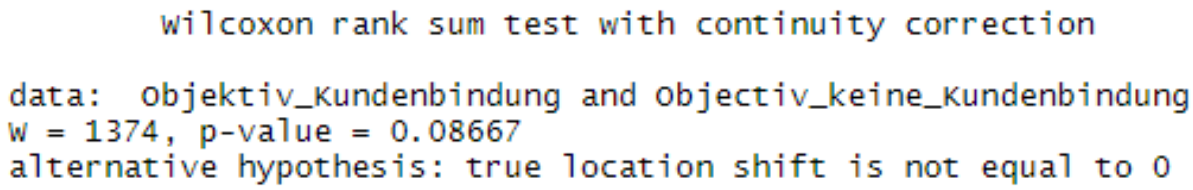

Result: The p-value is $>0.05$. The test shows that the hypothesis cannot be rejected.

More objective advice has no influence on customer loyalty.

Statement 3: 
Financial Markets, Institutions and Risks, Volume 3, Issue 4, 2019

ISSN (online) - 2521-1242 ISSN (print) - 2521-1250

Big Data \& Analytics ensures more comprehensive advice for bank customers.

What we want to investigate is: "How big is the influence of more comprehensive consulting on the question of higher customer loyalty?

Procedure: We have received a statement for each of the 122 bank clients regarding the more comprehensive advice. We know which of the bank customers have concluded that BD\&A ensures higher customer loyalty, and which do not. According to this assessment, we can "dichotomize" bank customers.

Now we test whether there is a significant difference in answering the question (after a more comprehensive consultation).

Background: 122 bank customers answered "yes" or "no" to the question of whether BD\&A ensures greater customer loyalty. So, we have two groups, the "Yes" and the "No" answering machine. We can now compare whether both groups would have answered the question of more objective counselling in roughly the same way. We would like to see the "yes-men" pleading for more comprehensive counselling.

What we have now tested is the question of a difference between the two groups.

Since the Wilcoxon rank sum test is a non-parametric test, no formulas can be used as hypotheses. The test checks whether the two same groups originate from the population.

Hypothesis: Both groups are from the same basic population. This means that, on average, the two groups formed would answer the question similarly.

Alternative hypothesis: Both groups do not originate from the same basic population.

In order to answer the hypothesis, a Wilcoxon rank-sum test was chosen because there is an ordinal scale level (Likert scale) with ranking.

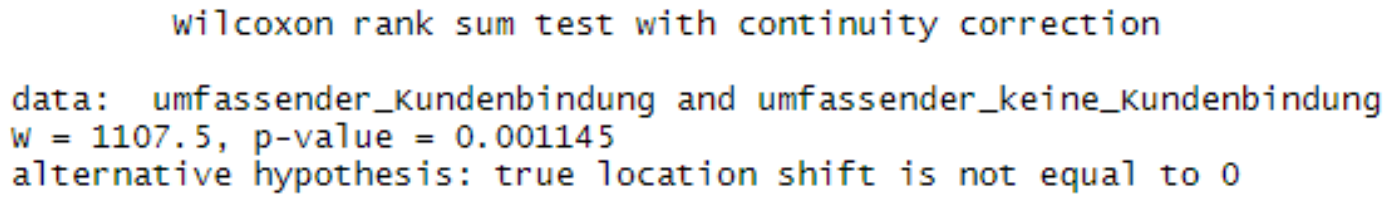

Result: The p-value is $<0.05$. The test shows that the hypothesis can be rejected.

More comprehensive advice has an impact on customer loyalty.

$\underline{\text { Statement 4: }}$

Big Data \& Analytics ensures more individual advice for bank customers.

What we want to investigate is: "How big is the influence of more individual consulting on the question of higher customer loyalty?

Procedure: For each of the 122 bank customers we received a statement regarding the more individual advice. We know which of the bank customers have concluded that BD\&A ensures higher customer loyalty, and which do not. According to this assessment, we can "dichotomize" bank customers.

Now we test whether there is a significant difference in answering the question (after a more individual consultation).

Background: 122 bank customers answered "yes" or "no" to the question of whether BD\&A ensures greater customer loyalty. So, we have two groups, the "Yes" and the "No" answering machine. We can now compare whether both groups would have answered the question of more objective advice in roughly the same way. We would like to see that the "yes-men" also plead for more individual advice.

What we have now tested is the question of a difference between the two groups.

Since the Wilcoxon rank sum test is a non-parametric test, no formulas can be used as hypotheses. The test checks whether the two same groups originate from the population. 
Hypothesis: Both groups are from the same basic population. This means that, on average, the two groups formed would answer the question similarly.

Alternative hypothesis: Both groups do not originate from the same basic population.

In order to answer the hypothesis, a Wilcoxon rank-sum test was chosen because there is an ordinal scale level (Likert scale) with ranking.

wilcoxon rank sum test with continuity correction

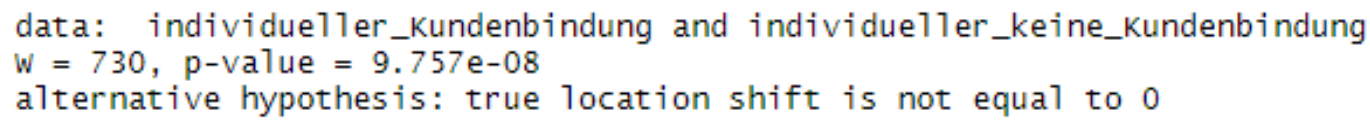

Result: The p-value is $<0.05$. The test shows that the hypothesis can be rejected.

More individual advice has an influence on customer loyalty.

Statement 5:

Big Data \& Analytics ensures more active advice for bank customers.

What we want to investigate is: "How big is the influence of more active consulting on the question of higher customer loyalty?

Procedure: For each of the 122 bank clients, we received a statement regarding more active advice. We know which of the bank customers have concluded that BD\&A ensures higher customer loyalty, and which do not. According to this assessment, we can "dichotomize" bank customers.

Now we test whether there is a significant difference in answering the question (after a more active consultation).

Background: 122 bank customers answered "yes" or "no" to the question of whether BD\&A ensures greater customer loyalty. So, we have two groups, the "Yes" and the "No" answering machine. We can now compare whether both groups would have answered the question of more objective advice in roughly the same way. We would like to see the "yes-men" also plead for more active consultation.

What we have now tested is the question of a difference between the two groups.

Since the Wilcoxon rank sum test is a non-parametric test, no formulas can be used as hypotheses. The test checks whether the two same groups originate from the population.

Hypothesis: Both groups are from the same basic population. This means that, on average, the two groups formed would answer the question similarly.

Alternative hypothesis: Both groups do not originate from the same basic population.

In order to answer the hypothesis, a Wilcoxon rank-sum test was chosen because there is an ordinal scale level (Likert scale) with ranking.

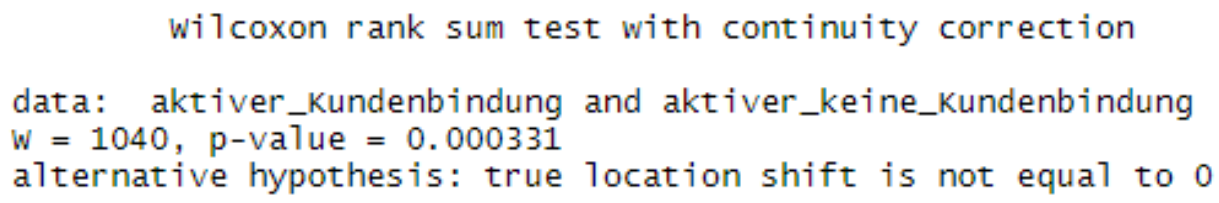

Result: The p-value is $<0.05$. The test shows that the hypothesis can be rejected.

More active advice has an influence on customer loyalty.

\section{Statement 6:}

The age of the customer does not play a role in customer loyalty.

The respondents answered the age question independently. 
Financial Markets, Institutions and Risks, Volume 3, Issue 4, 2019

ISSN (online) - 2521-1242 ISSN (print) - 2521-1250

We refer to the average age of bank customers who responded positively to the question of greater customer loyalty through BD\&A as $\mu$ pos. Similarly, we define the mean age of bank customers who responded negatively as $\mu$ neg.

We test whether the customers who answered positively and those who answered negatively are on average the same age.

Hypothesis: $\mathrm{H}_{0}: \underline{\mu}$ neg $=\underline{\mu} \underline{p o s}$

Alternative hypothesis: $H_{1}: \mu \_$neg $\neq \mu \underline{\text { pos }}$

To answer the hypothesis, a (two-sided) t-test was performed. The test variable is the standardized difference between the mean values. Under the hypothesis, the test variable is "student-t-distributed.

We do not assume that the standard deviations of the two groups agree. Therefore, we use the Welch approximation of the degrees of freedom.

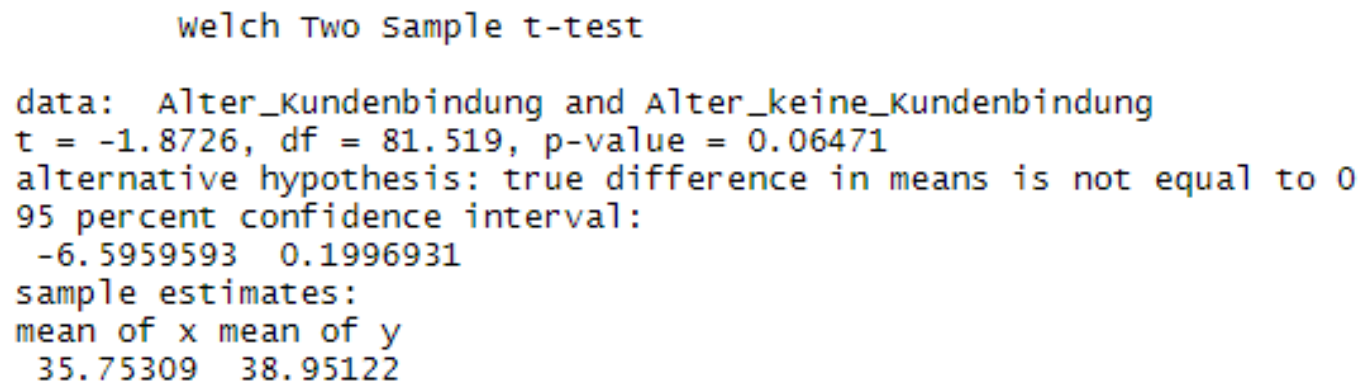

Result: The hypothesis was statistically proven, since the $\mathrm{p}$-value $=0.06471$ and thus $>0.05$.

Age has no significant influence on the answer to the question. This can be seen in Graph 7. Although the graphs on the figure are similar. You think you see a difference, but it's not significant.

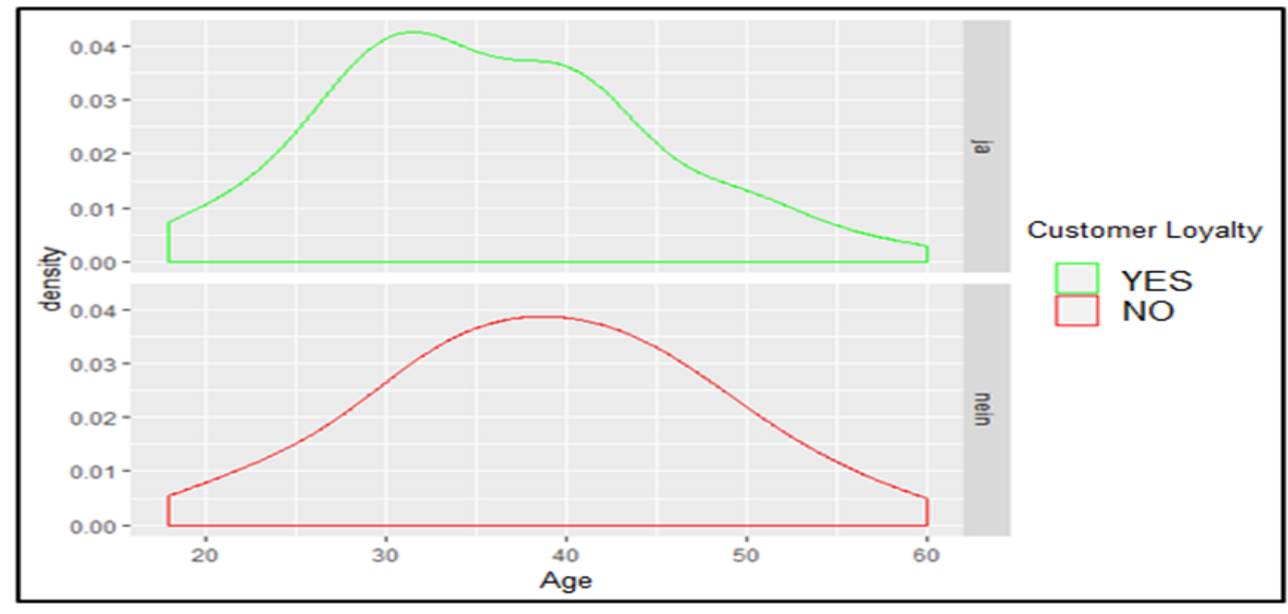

Graph 7. Influence of age on customer loyalty

Source: compiled by the authors.

In their study, Fuschi and Tvaronavičienė divided the bank investigated into three main areas, namely [1] banking applications, [2] financial markets and [3] network infrastructure (Fuschi and Tvaronavičienè 2014). According to the experience of our study, this structure has a potential to define a further aspect. Our findings lack a fourth aspect, the [4] role of the bank advisor, which could be found in further research.

Unfortunately, companies that focus primarily on profits are ignorant of environmental, ethical and social issues. As a result of the development of the concept of sustainability, compliance with standards of ecological, ethical and social responsibility is increasingly becoming the focus of attention. Trust is a basic prerequisite for the business activities of banks. For this reason, banks are forced to build long-term, high-quality relationships with their employees, stakeholders and customers. The relationship with bank customers can therefore be perceived as an effective means. In any case, a concept of sustainable development should be well 
planned and consistently implemented in the long term (Rudawska and Renko, 2012). Our study has proven that the use of Big Data \& Analytics can ensure lasting customer loyalty. But here it can be critically noted that bank customers in Germany usually do not know that their bank uses Big Data \& Analytics. Big Data \& Analytics alone does not sell a product. This is where the human capital of a bank comes into play.

The bank should focus on employee training and thus take into account the perspective of the bank advisor (02). The focus should be on understanding specific customer needs. This can only be done through individual advice and suitable banking products. This allows customers to be given a permanent comfort status and to be tied to the bank (Corneliu, 2013). McDonald also believes that in the context of knowledge transfer, the majority of teaching activities in the areas of ethics and social responsibility are neglected and the focus should be on the learner's perspective. In his article, he describes a possible change scenario. In order to change the ethical potential of learners, their own beliefs, mindsets, doubts, values and priorities must be revealed. This is the only way to develop a force that can change behaviour (McDonald, 2015). We are convinced that knowledge transfer between professors and students has many parallels with knowledge transfer between trainers, coaches and bank advisors. The author calls the ability to see one's own personal ethical behavior in the context of one's own life the greatest value. If this is ensured, it is easier to put oneself in the customer's perspective. This should be ensured by careful accompanying measures. This is the only way to ensure that customers are actually sold with the best of knowledge and conscience only those products for which they actually have an affinity.

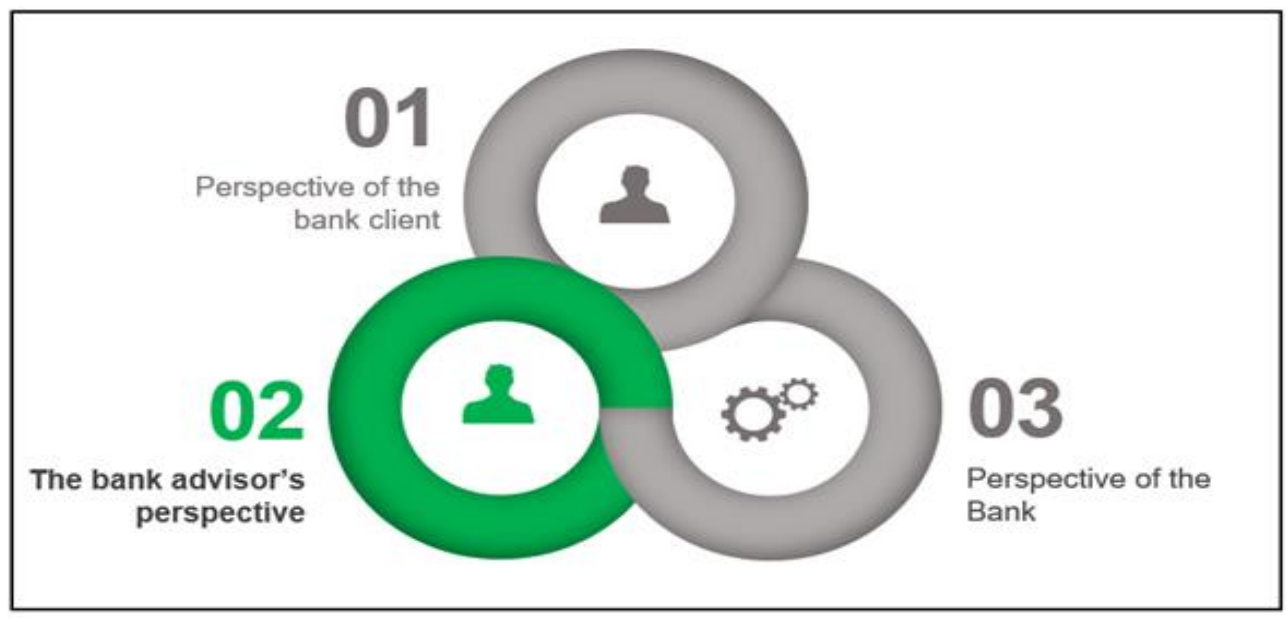

Figure 2. Various perspectives in customer advisory services

Source: compiled by the authors.

In the area of teaching, the target group of the so-called "e-society4" poses a particular challenge. The "egeneration" needs a different approach to teaching. According to the authors, the debate about one's own consumption is a key to achieving sustainability (Kerekes and Wetzker, 2013). Here, too, teaching can be transferred to banking practice. When bank advisors deal with their own consumer behaviour, there is automatically a customer perspective. And transferred to the bank, one goal could be to advise bank customers as fairly and comprehensively as you would like to be advised yourself. A further aspect is that demographic aspects are noticeable in the job description of the banker. Some bank advisors are already members of the ESociety.

\section{Conclusions}

Most of survey participants agreed with the statement as to whether Big Data \& Analytics provides a more objective, more comprehensive, more individual and more active consultation. We have proven that Big Data $\&$ Analytics increases customer loyalty from the point of view of bank customers. And we can say that age did not play a significant role in answering the questions. Measured against the principles of client advice, more comprehensive, individual and active advice has an influence on customer loyalty. A more objective customer advisory service, on the other hand, is not.

Graph 8 shows a two-dimensional visualization of how bank customers responded to the survey. Green (BD\&A increases customer loyalty) and red (it doesn't). Each of the 122 bank customers has a coloured dot representing him.

${ }^{4}$ Abbreviation for Electronic Society 
We have considered our own logic in the principles of client consulting. The value 4 means (4 times very good), the value 16 means (4 times lowest value).

The size of the respective colour dots visualizes the answers (the individual answers to questions 2-5 were consolidated). The larger the colour dots, the greater the doubt (related to the principles of customer service). Most customers who have decided "per" customer retention (shown in green in the figure) have the impression that BD\&A also makes a positive contribution to the majority of customer advisory principles. In the case of the red bank customers who voted "contra" customer loyalty, the other way around. It is noticeable that more critics (Big Bubbles) nevertheless say that customer loyalty can be increased through Big Data \& Analytics. That's interesting. In order to be able to identify each customer, a further differentiation possibility in "R" was used over the age. The age was not shown as it is not statistically significant for the question of customer loyalty. Here it serves as an auxiliary size, so that the colour points do not lie on top of each other. We used multi-dimensional scaling. The more similar the bank customers answered, the closer they are to each other.

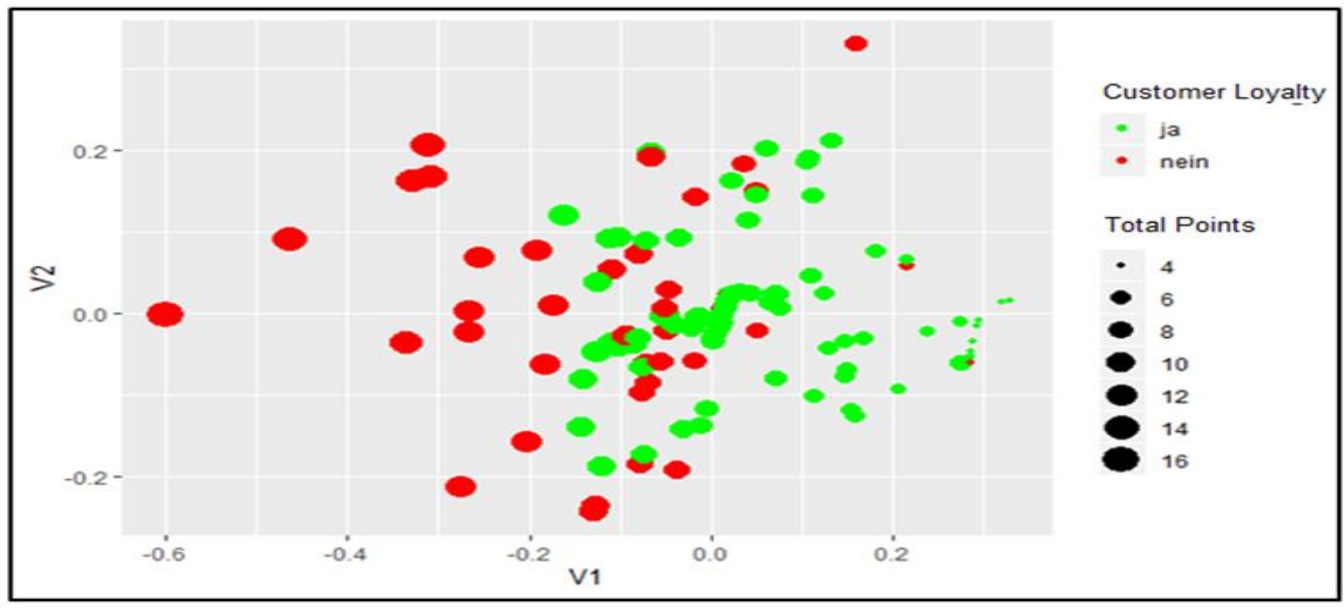

Graph 8. Two-dimensional scaling

Source: compiled by the authors.

The responsibility of CSR is still controversially discussed and there are supporters and disapprovers. However, this possible influence of CSR on companies is not a self-runner. We note that the discussions about CSR are quite old, but still undecided (Hammerström et al., 2019).

According to the model of the triple bottom line it is important to pay attention to man, planet and profit. In the tripartite construct, ecological, social and economic sustainability form the basis. If one refers to the human factor, for example, in the past the improvements in working conditions and the prohibition of child labour have been the main issues (Tóth, 2019). In the human context we would not like to describe the customer perspective. Better said, the fair, individual and comprehensive advice to customers. This aspect also stands for social sustainability, which goes hand in hand with economic sustainability. Accordingly, our research results can be embedded in existing sustainability models.

In practice, for example, academic knowledge or philosophical theories can be used to educate people to take responsibility. The aim is to support learners' insights and not to override them (McDonald, 2015). If one regards the mathematical-statistical models as an academic basis, Big Data \& Analytics combined with a sense communication to be carried out can be absolutely target-oriented. Ergo also pays tribute to McDonald's broader perspective on the challenges of digitalization. As discussed in the introductory section, Green Banking also describes the combination of changing customer habits in the banking business with operational, technological improvements (Singh and Singh, 2012). If this definition applies, then our research findings can also be used to incorporate Big Data \& Analytics as a sustainable customer loyalty instrument under the term Green Banking.

\section{Limitations and directions for further research}

If we take a critical look at our research results, it can be noted that the explanation of Big Data \& Analytics is only explained with the passage "Big Data \& Analytics" (the analysis of large amounts of data) is a collective term for statistical-mathematical methods that enable the bank advisor, for example, to forecast which customers are "affine" to a certain product and is possibly rudimentary. 
Financial Markets, Institutions and Risks, Volume 3, Issue 4, 2019 ISSN (online) - 2521-1242 ISSN (print) - 2521-1250

In the age of digital transformation, external business coaching for executives is a very effective tool. When providing support, care must be taken to ensure that managers are accompanied during the digital transformation process. In other studies, coaching programs helped executives improve their performance (Ionicioiu and Mbăruş, 2016). Thus, one could explicitly shed light on the role of executives in the context of further research.

Hammerström et al. assume that it is possible to close the theoretical gap between CSR and digitisation. To this end, the awareness of the workforce for CSR must be promoted. This can be done by internal or external motivators (Hammerström et al., 2019). In our opinion, this can be achieved through training measures such as training and coaching. This would be a starting point for a study to investigate the effectiveness of internal or external motivators.

Another aspect that we have touched on in our research is the subject of "brand". A team is a team when there is brand awareness the employees must be inspired for the business plan in order to grow together and support the company's further social responsibility (Zwerenz, 2019). Bank employees who advise bank customers are not lone fighters. You act as a team. In this respect, we assume that this knowledge can be transferred. One assumption is that if bank advisors have a high level of brand awareness and identification with the company's values, this can have a positive influence on a bank's CSR business activities. However, this assumption was not examined in the context of this research and can form the basis for further investigation.

The "modern enterprise" has a key role in the development of CSR by creating a new entrepreneurial spirit. Companies have enough power to take the necessary steps forward, and modern companies can learn a lot from "the small company" (Tóth, 2007). However, a definition of 'modern enterprise' cannot be found in Tóth's factory. We believe that banks in Germany can be described as "modern enterprises". Here would be another approach for a study. From Mavlutova and Volkova's point of view, the banking sector would benefit from the development of various competencies, including Big Data \& Analytics. In order to make optimum use of the various technical innovations, commercial banks must develop their own competencies around each activity in the value chain. Effective and proactive competence-based management should be provided Only in this way can it be ensured that the necessary competences are available (Mavlutova and Volkova, 2019). How competence-based management parameterizes itself also offers scope for further studies.

\section{Acknowledgement}

In the context of this research, practical relevance was enormously important to us. We would therefore like to thank Data Scientist Kevin Schulz (Berlin, Germany), who successfully develops Big Data \& Analytics for a major banking group in Germany. Thank you for the sparring and the valuable professional exchange.

\section{References}

1. Corneliu, B. (2013). The quality of banking services-A basic premise of a Bank sustainability. Annals of the University of Oradea-Economic Science Series, 22, 430-439, http://steconomiceuoradea.ro/ anale/volume/2013/n2/041.pdf.

2. David, O. A., Ionicioiu, I., Imbăruş, A. C., \& Sava, F. A. (2016). Coaching bank managers through the financial crisis: effects on stress, resilience and performance. Journal of rational-emotive \& cognitivebehavior therapy, 34(4), 267-281, https://doi.org/10.1007/s10942-016-0244-0

3. Dubey, R., Gunasekaran, A., Childe, S. J., Papadopoulos, T., Luo, Z., Wamba, S. F., \& Roubaud, D. (2017). Can big data and predictive analytics improve social and environmental sustainability?. Technological Forecasting and Social Change, https://doi.org/10.1016/j.techfore.2017.06.020

4. Fuschi, D. L., \& Tvaronavičienè, M. (2014). Sustainable development, Big Data and supervisory control: service quality in banking sector. Journal of security and sustainability issues, 3, 5-14, https://doi.org/10.9770/jssi.2014.3.3(1)

5. Giebe, C. (2019). The Chief Digital Officer-Savior for the Digitalization in German Banks?. Journal of Economic Development, Environment and People, 8(3), 6-15, http://dx.doi.org/10.26458/jedep.v8i3.633 hh

6. Principles of customer advisory services (banking knowledge). http://www.bankazubi.de/wissenspool/ artikel.php? opid=1achgebietid=1atid=9rtikelid=17 [Accessed on 2019, November] 
Financial Markets, Institutions and Risks, Volume 3, Issue 4, 2019

ISSN (online) - 2521-1242 ISSN (print) - 2521-1250

7. Gupta, J. (2015). Role of Green banking in Environment Sustainability-A study of selected Commercial Banks in Himachal Pradesh. International Journal of Multidisciplinary Research and Development, 8(2), 349-353, e-ISSN: 2349-4182, p-ISSN: 2349-5979, 10.13140/rg.2.2.33734.78407

8. Hammerström, L., Giebe, C., Zwerenz, D. (2019). Influence of Big Data \& Analytics on Corporate Social Responsibility. SocioEconomic Challenges, 3(3), 47-60, https://doi.org/10.21272/sec.3(3).47-60.2019

9. Hammerström, L. (2018). Organizational Design of Big Data and Analytics Teams. European Journal of Social Science Education and Research, 5(3), 132-149, ISSN 2312-8429. Available at: http://journals.euser.org/index.php/ejser/article/view/ejser-2018.v5i3-524

10. Jeble, S., Dubey, R., Childe, S. J., Papadopoulos, T., Roubaud, D., \& Prakash, A. (2018). Impact of big data and predictive analytics capability on supply chain sustainability. The International Journal of Logistics Management, 29(2), 513-538, https://doi.org/10.1108/IJLM-05-2017-0134

11. Kerekes, S., \& Wetzker, K. (2013). How to teach a complex discipline in a changing learning environment: the example of sustainability. Journal of Environmental Sustainability, 3(3), 2, https://doi.org/10.14448/jes.03.0001

12. Mavlutova, I., \& Volkova, T. (2019). Digital Transformation of Financial Sector and Challengies for Competencies Development. In 2019 7th International Conference on Modeling, Development and Strategic Management of Economic System (MDSMES 2019). Atlantis Press, https://doi.org/10.2991/mdsmes19.2019.31

13. McDonald, R. (2015). Leveraging change by learning to work with the wisdom in the room: educating for responsibility as a collaborative learning model. Journal of business ethics, 131(3), 511-518, https://doi.org/10.1007/s10551-014-2477-0

14. Rudawska, E., \& Renko, S. (2012). Sustainability as the Direction for the Long-term Success in Banking: Poland vs. Croatia. Folia Oeconomica Stetinensia, 11(1), 97-117, https://doi.org/10.2478/v10031012-0002-0

15. Singh, H., \& Singh, B. P. (2012). An effective \& resourceful contribution of green banking towards sustainability. International Journal of Advances in Engineering Science and Technology, 1(2), 41-45, ISSN:2319-1120, https://pdfs.semanticscholar.org/4775/28c3a2640d2fae00035e70c3a41ade4d7591.pdf

16. Tóth, G. (2019). Circular Economy and its Comparison with 14 Other Business Sustainability Movements. Resources, 8(4), 159, https://doi.org/10.3390/resources8040159

17. Tóth, G. (2007). The Truly Responsible Enterprise: About unsustainable development, the tools of Corporate Social Responsibility (CSR) and the deeper, strategic approach. Budapest: KÖVET Egyesület a Fenntartható Gazdálkodásért.

18. Wilson, A. M., Zeithaml, V., Bitner, M., \& Gremler, D. (2008). Services marketing: 1st European edition, https://pureportal.strath.ac.uk/en/publications/services-marketing-1st-european-edition

19. Zeithaml, V. A., Berry, L. L., \& Parasuraman, A. (1993). The nature and determinants of customer expectations of service. Journal of the academy of Marketing Science, 21(1), 1-12, https://doi.org/10.1177/0092070393211001

20. Zwerenz, D. (2019). Brand Management: Organizational Changes in Project Management. Marketing and Management of Innovations, issue, 253-265, http://doi.org/10.21272/mmi.2019.2-22. 